\title{
Long-delay, one-trial conditioned preference and retention in monkeys (Cebus apella)
}

\author{
M. R. D'AMATO and JAY BUCKIEWICZ \\ Rutgers University, New Brunswick, New Jersey 08903
}

\begin{abstract}
Cebus monkeys explored a small T-maze for $5 \mathrm{~min}$, and their preference for the striped or black arm of the maze was assessed. On the next day, the experimental animals were placed into the nonpreferred arm for a 1-min period (exposure to the CS), removed from the T-maze for a 30-min delay interval, and then returned to the startbox of the maze, where they received a food reward (UCS). One control group (CS only) received the placement experience but was not rewarded after the 30-min period. A second control group (noncontingent UCS) received the reward in the startbox but not the placement experience. A second preference test showed that the experimental, but not the control, animals reversed their original preference, now showing a preference for the arm associated with reward. A retention test given 4 months after three such training-test trials revealed considerable retention of the preferences exhibited by the experimental and CS-only control subjects.
\end{abstract}

Despite reservations expressed in some quarters (e.g., Bitterman, 1975; Mitchell, 1977), it seems well established that bona fide long-delay conditioning occurs in the conditioned taste-aversion paradigm. There is less consensus as to whether long-delay conditioned taste aversions represent specialized learning mechanisms rather than special sets of parameter values or the outcome of unusual interactions among traditional learning variables (cf. Krane \& Wagner, 1975; Testa \& Ternes, 1977). Lett's report (1975) that rats are capable of some degree of cue-correlated position learning with delays of reward as long as $1 \mathrm{~h}$ suggests that, with appropriate parameter values, acquisition of instrumental behavior might be less vulnerable to delay of reward then hitherto thought. However, our attempts to obtain visual (nonspatial) discrimination learning in cebus monkeys with a reward delay of only $16 \mathrm{~min}$ have been uniformly unsuccessful (D'Amato \& Cox, Note 1), although the same animals have been shown to be capable of efficient visual discrimination learning with delays in the neighborhood of 1 min (D'Amato \& Cox, 1976).

But it may not be entirely appropriate to compare conditioned taste aversions, which represent the acquisition of an affective response, with the acquisition of instrumental behavior. Although instrumental behavior is presumably ultimately guided and controlled by affective input, the coupling may not always be immediate and direct. Thus, in taste-aversion studies, because of the nature of the indicant response, expression of the nega-

This research, reported at the 1978 meetings of the Psychonomic Society, was supported by grants from the National Science Foundation and the Rutgers University Research Council. J.B. is now at Bowling Green University. Address reprint requests to M. R. D'Amato, Department of Psychology, Rutgers University, Busch Campus, New Brunswick, New Jersey 08903. tive affective response conditioned to the CS is completely unimpeded. The experiments are so designed that on test trials the animal very soon makes contact with the CS, and the existence of a conditioned negative affective response is revealed simply by the termination of that contact. When the establishment of an instrumental response is required, on the other hand, expression of the conditioned affective response is delayed until the indicant instrumental response is acquired (cf. Testa \& Ternes, 1977). If put on similar terms, it is possible that positive affective responses, that is, preferences, can be conditioned as readily as taste aversions and with the burden of a substantial CS-UCS delay.

Conditioned preferences based on exteroceptive cues have traditionally been investigated within the secondary (conditioned) reinforcement paradigm (cf. Wike, 1966). For example, an animal is subjected to noncontingent pairings of a tone (CS) and food (UCS), and the conditioned reinforcement properties developed by the tone because of these pairings are subsequently evaluated by the ability of the tone to reinforce an instrumental response, such as barpressing. A substantial number of pairings of the CS and the primary reinforcer was typically necessary to demonstrate significant conditioned reinforcement; moreover, the degree of conditioned reinforcement achieved was greatly attenuated if a delay of even a few seconds was interposed between presentation of the CS and presentation of the primary reinforcer (e.g., Jenkins, 1950). These results may have discouraged investigators from entertaining the notion that a significant amount of preference behavior could be conditioned within a single trial and with a substantial delay of reinforcement.

This possibility receives some support from more recent studies that demonstrate one-trial appetitive conditioning (Albert \& Mah, 1972; Pinel, 1969; Tenen, 
1965). For example, Albert and Mah allowed rats to explore a "nook" in one wall of a square box containing a familiar, but empty, drinking spout. After a single such trial, the animals later explored the empty nook more than did controls that had not encountered the drinking spout on the training trial, a result that may be interpreted as one-trial conditioned preference (for the vicinity in which the spout was located). One reason for the success of these studies in demonstrating one-trial conditioned preference may be that the indicant response, approaching and remaining in the area where the drinking spout had been located, was simple enough to allow full expression of the affective response conditioned during the training trial.

We employed a similar indicant response in our study, which addressed the following question: Can a conditioned preference be established in monkeys in a single trial and with a 30-min delay separating the CS and the primary reinforcer? In designing the experiment, we took several cues from the conditioned taste-aversion literature. Taste-aversion conditioning is facilitated by novel, as compared with familiar, CSs (e.g., Domjan, 1972); we therefore constructed a T-maze apparatus that was an entirely novel environment for all the animals. Conditioned taste aversion is a positive function of the intensity of the toxic agent that serves as the UCS (e.g., Dragoin, 1971), which led us to employ a highly preferred and salient food as the reward object.

\section{METHOD}

\section{Apparatus}

The T-maze, constructed of wood, was $37 \mathrm{~cm}$ in height and width, with $59-\mathrm{cm}$ arms and a $76-\mathrm{cm}$ stem. Transparent guillotine doors were located at the entrance of the arms, and a startbox was formed by a third transparent guillotine door located $38 \mathrm{~cm}$ into the stem. The top of the maze was enclosed with transparent Plexiglas. The animals were introduced into the $T$ maze and removed from it through opaque doors that formed the end wall of each arm and the rear wall of the stem. The stem of the maze was painted dark gray, the right arm, black; the left arm was vertically striped with alternating gray and white $5-\mathrm{cm}$ bars.

A small test room $(3 \times 4 \mathrm{~m})$, unfamiliar to the subjects, housed both the T-maze and the holding cage in which they spent the delay period. Extraneous noises were masked by a white-noise source in the test room, which was moderately illuminated by overhead fluorescent lights.

\section{Subjects}

Of the 15 monkeys (Cebus apella) that began the experiment, 3 were eliminated before the first test day was completed-one because it escaped from the apparatus, one because of its extreme baseline preference, and the third because it repeatedly refused to enter the T-maze. The 12 animals that completed the experiment consisted of 7 females and 5 males, ranging in age from about $3-15$ years $(1.6-3.9 \mathrm{~kg})$, and differing enormously in previous experimental experience. Some animals had had years of experience in our automatic discrimination-learning apparatus, while others were experimentally naive. None of the animals had ever been in the $T$-maze or in a similar apparatus. During the experiment, they were housed individually and fed a daily ration of Purina monkey chow (1-2 h after the experimental session) sufficient to maintain them within $90 \%-100 \%$ of their ad-lib body weights.

\section{Procedure}

Day 1 was devoted to obtaining a baseline preference measure for each of the 12 animals, all of which were treated identically. An animal was introduced into the startbox of the T-maze and, about $30 \mathrm{sec}$ later, the startbox door was raised. The animal was allowed to explore the maze for $5 \mathrm{~min}$ (with the startbox door closed), and the duration of time spent in each arm of the maze and in the center section was measured. An animal was considered to be in an arm when at least three of its paws were located in that arm; there was little difficulty in making this discrimination, as the animals normally penetrated the arm fully or not at all. Time spent in each arm was accumulated on .1-sec electric clocks, which one observer (J.B.) activated by pressing hand-held pushbutton switches. A second observer (M.R.D.) was present during the preference tests, both observers standing directly behind the startbox of the T-maze. At the completion of the 5-min baseline preference evaluation, the animal was returned to its home cage in the colony room. The animals were transported to and from the test room in a small carrying cage, from which they could be introduced into (or removed from) the maze via the opaque doors located at the end of each arm and the stem.

Three groups of four animals each were formed, roughly equated with regard to their baseline preference scores and previous experimental history. On Day 2, the animals of the experimental group (Group E) were placed into the nonpreferred arm of the T-maze, as assessed by their Day-1 behavior, remaining there for $1 \mathrm{~min}$ with the transparent guillotine door of the arm closed. This $1-\mathrm{min}$ exposure to the originally nonpreferred arm may be thought to correspond to exposure to the CS in conditioned taste-aversion studies. At the end of the 1-min period, the animal was removed from the T-maze and placed into the holding cage in the test room, where it was left undisturbed for $30 \mathrm{~min}$. At the end of the $30-\mathrm{min}$ delay interval, the animal was placed in the startbox of the T-maze, where it found 10 raisins in a metal cup (the UCS). After ingesting the raisins, the animal was removed from the startbox and held in the carrying cage for a 1-min period, during which time the food cup was removed from the startbox. Finally, the animal was reintroduced into the startbox; 10 to 15 sec later, the startbox door was raised and the animal was given a $3-\mathrm{min}$ preference test, which was identical in all respects to the 5-min baseline preference test given on Day 1. Preference-test duration was reduced from 5 to $3 \mathrm{~min}$ in order to mitigate possible extinction effects of the test.

The animals of Control Group 1 (C1) were treated exactly as were the experimental subjects, except that they did not receive the raisin reward in the startbox. These animals were placed into the nonpreferred arm for the 1-min period, removed to the holding cage for the 30-min delay interval, and then introduced into the empty startbox for a period of time equivalent to that required by the experimental animals to consume the raisin reward. They were then removed from the startbox to the carrying cage for a $1-\mathrm{min}$ period, reintroduced into the startbox, and given their 3 -min preference test. These animals are analogous to the CS-only control subjects employed in taste-aversion studies.

The animals of Control Group 2 (C2) were the "noncontingent" controls. They received the raisin reward, but without being first exposed to the CS. These animals were transported to the test room and placed directly into the holding cage for the 30 -min "delay" interval. At the end of the interval, they were introduced into the startbox, where they found the 10 raisins. After consuming the raisins, they were removed from the startbox for a 1-min period, then reintroduced into the startbox and given the standard 3-min preference test. The purpose of Groups $\mathrm{C} 1$ and $\mathrm{C} 2$ was, of course, to evaluate the effect of simply being exposed to the CS (the originally nonpreferred arm) or to the UCS (the raisin reward).

On Days 3 and 4 , the animals in the three groups received training-test trials conducted in precisely the same manner as on Day 2. Thus, the experiment consisted of one baseline session (Day 1) followed by three training-test trials, one per day (Days 2-4). 


\section{Retention Test}

Retention of the preferences established during the training phase was assessed by a retention test administered approximately 4 months after the last training-test trial (mean retention interval $=131$ days). Although the retention interval varied among the individual animals (115-144 days), the maximum difference in the average retention interval among the three groups was 5 days. The retention test consisted of a 3-min preference test conducted in the same way as the earlier preference tests.

\section{RESULTS}

\section{Acquisition}

Preference for one side of the T-maze was defined as the amount of time spent in that arm divided by the total amount of time spent in both arms; time spent in neither arm (in the center section) was excluded. Figure 1 presents the group data in terms of percent preference for the originally nonpreferred arm. During the Day-1 baseline preference test (B in Figure 1), there was, of course, little difference among the groups, as they were equated on this measure. Strength of preference for the nonpreferred arm varied among individual animals during baseline from $6 \%$ to $48 \%$, and 8 of the 12 subjects preferred the left (striped) arm. However, as a result of a single placement in the nonpreferred arm followed 30 min later by reward in the startbox, Group $\mathrm{E}$ showed a sharp reversal of preference, whereas the two control groups did not. A simple analysis of variance performed on the preference scores obtained on the first test trial showed that the differences among the groups were reliable $[F(2,9)=5.16, p<.05]$. As Figure 1 suggests, Group $\mathrm{E}$ was significantly different from both Group $\mathrm{C} 1$ and Group $\mathrm{C} 2$ ( $\mathrm{p}<.02$ in both cases). Moreover, a $t$ test comparing the preference scores on the first test trial with a chance $(50 \%)$ baseline indicated that the

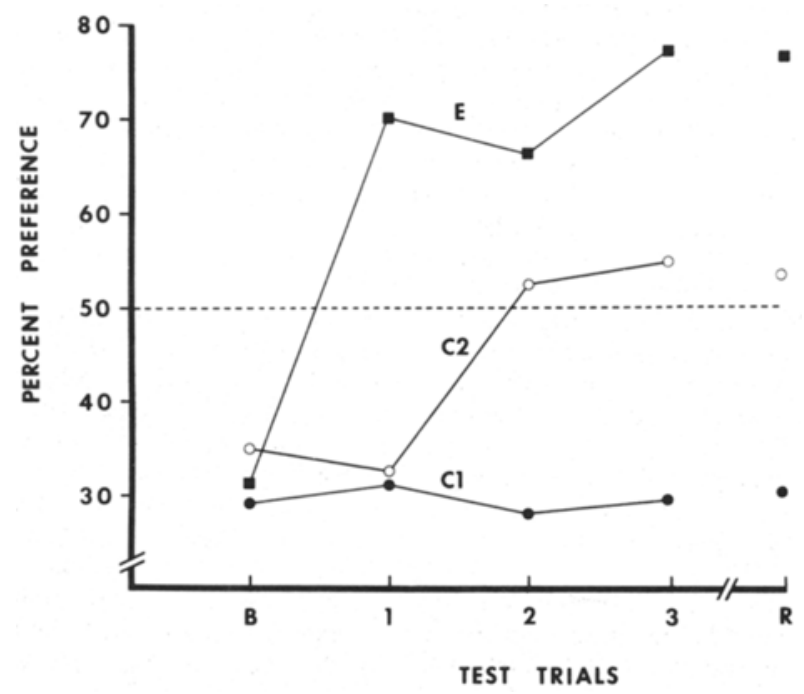

Figure 1. Percent preference scores for the experimental (E) and control groups obtained during baseline (B), test trials, and retention $(\mathbf{R})$.

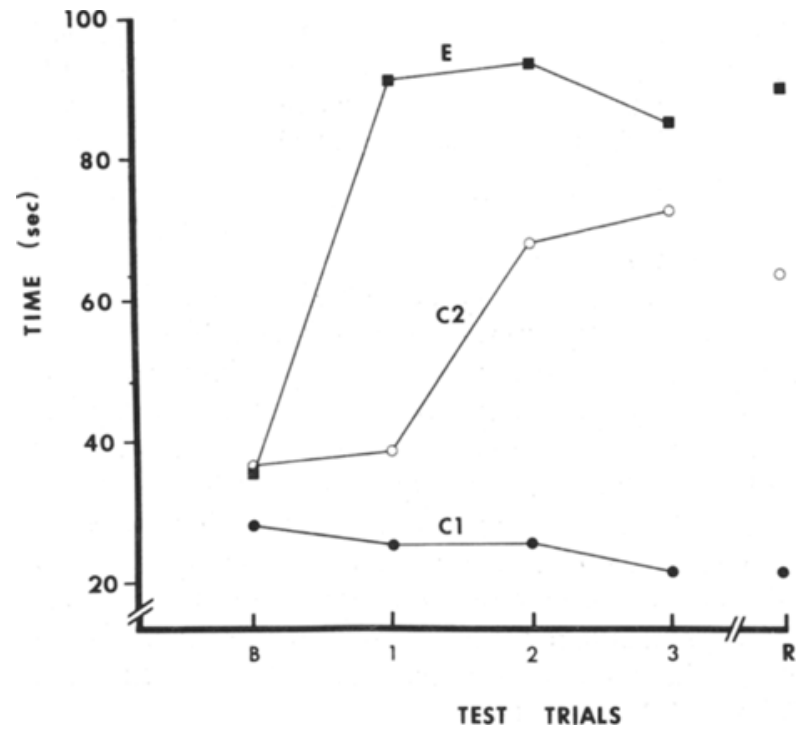

Figure 2. Amount of time spent in the originally nonpreferred arm during baseline (B), test trials, and retention test $(R)$, for the experimental (E) and control groups.

experimental animals developed a significant preference for the arm that was originally nonpreferred $[t(3)=3.95$, $\mathrm{p}<.05]$.

The results of test trials 2 and 3 are also instructive. The experimental animals maintained their newly formed preference, whereas the $\mathrm{Cl}$ animals, which were placed but not rewarded, maintained their original preference. On the other hand, the $\mathrm{C} 2$ animals, which received reward but no placement, extinguished their original preference. As a result of this change in Group C2, the overall analysis of variance for test trials 2 and 3 was not significant, but the comparison between the experimental group and Group $\mathrm{C} 1$ was significant on both days $(\mathrm{p}<.05)$. An overall analysis of variance based on all three test trials produced essentially the same picture.

Although the percent preference scores are rather impressive, they do not indicate whether the experimental animals increased the amount of time spent on the originally nonpreferred side, as they are only relative preference measures. The duration of time spent on the originally nonpreferred side of the T-maze is shown in Figure 2. The baseline scores obtained on Day 1 were multiplied by .6 to account for the fact that a 5 -min preference test was given during baseline compared with 3-min preference tests on subsequent days. It is clear from the figure that as a result of a single placement experience followed $30 \mathrm{~min}$ later by a food reward, the experimental animals more than doubled the (prorated) amount of time spent in the originally nonpreferred arm. On the other hand, there was virtually no change in Groups $\mathrm{C} 1$ and $\mathrm{C} 2$. The test-trial 1 differences are significant $[F(2,9)=4.58, p<.05]$, as are the differences between Group $\mathrm{E}$ and each of the control groups separately $(\mathrm{p}<.01$ and $\mathrm{p}<.05$ for the $\mathrm{C} 1$ and $\mathrm{C} 2$ compari- 
sons, respectively). The time duration scores show essentially the same pattern as the percent preference scores over test trials 2 and 3 , except that in the present case, the group differences are significant $[\mathrm{Fs}(2,9)=4.52$ and 4.26 , respectively, ps $<.05]$.

\section{Retention Test}

The percent preference data obtained from the retention test are also presented in Figure 1 (R). Clearly, there was little change in the groups' preferences over the 4-month retention interval. As on test trial 3, the difference between the experimental and $\mathrm{Cl}$ groups was significant $(\mathrm{p}<.05)$, although the overall $F$ was not $[F(2,9)=2.57]$. The time duration scores for the retention test are given in Figure $2(\mathrm{R})$. It is apparent that the differences in absolute time that existed on the third test trial were maintained over the 4-month retention interval. In the present case, the ANOVA was significant $[F(2,9)=7.17, \mathrm{p}<.05]$.

\section{DISCUSSION}

The results obtained in the training phase were far more powerful than we expected. Apart from the fact that there were only four animals in each group, there was an enormous variation in the background and ages of the animals, although we equated these factors as much as possible. Of the four animals in the experimental groups, two were veterans of a considerable amount of past experimental experience, and the other two were much younger animals who had little or no previous experimental experience. Yet, all four animals showed a substantial reversal of preference as a result of a single placement experience followed by a reward $30 \mathrm{~min}$ later. The retention data were equally surprising. The preference developed in the experimental animals by the three placement-reward experiences showed no sign of abatement after a 4-month retention interval, and the initial preference of Control Group 1 was equally maintained over that substantial interval.

Although it is not possible to specify with precision the factors responsible for the present results, the use of a simple indicant response already present in the animals' repertoire doubtless was of paramount importance. That the experimental apparatus constituted a novel environment for the animals was, we believe, also important, as well as was the fact that the animals spent the delay interval in the (quiet) test room, which may have served both to facilitate "poststimulus processing" and to isolate the training experience from potentially interfering events.

Despite the remarkable reversal of preference following a single, long-delay conditioning trial, the analogy between the present results and conditioned taste aversions should not be pushed too far. Among the many differences in the two paradigms is the circumstance that our preference tests were administered soon after application of the UCS, whereas in conditioned taste-aversion studies, the test trials are withheld for a day or more after the conditioning trials. Some delay in taste-aversion studies is unavoidable in order to allow the animal to recover from the malaise induced by the toxic agent, whereas we were under no such obligation. The significance of this difference in procedure, if any, needs to be assessed, as well as such issues as the nature of the delay gradients obtainable in conditioned preference studies, the role of amount of CS exposure, number of conditioning trials, and other variables whose effects on conditioned taste aversions have been investigated in detail. Because proper investigation of these questions requires substantial numbers of subjects, it will be necessary to replicate the present results with subjects that are more abundantly available than monkeys. Using rats as subjects, we have recently made some progress in this direction.

\section{REFERENCE NOTE}

1. D’Amato, M. R., \& Cox, J. K. Long-delay discrimination performance and acquisition in monkeys. Paper read at the meeting of the Psychonomic Society, St. Louis, Missouri, November 1976.

\section{REFERENCES}

Albert, D. J., \& MAн, C. J. An examinination of conditioned reinforcement using a one-trial learning procedure. Learning and Motivation, 1972, 3, 369-388.

Bitterman, M. E. The comparative analysis of learning: Are the laws of learning the same in all animals? Science, 1975, 188, 699-709.

D'Amato, M. R., \& Cox, J. K. Delay of consequences and shortterm memory in monkeys. In D. L. Medin, W. A. Roberts, \& R. T. Davis (Eds.), Processes in animal memory. Hillsdale, N.J: Erlbaum, 1976.

Domjan, M. CS preexposure in taste-aversion learning: Effects of deprivation and preexposure duration. Learning and Motivation, 1972, 3, 389-402.

Dragoin, W. Conditioning and extinction of taste aversions with variations in intensity of the CS and UCS in two strains of rats. Psychonomic Science, 1971, 22, 303-305.

JENKINS, W. O. A temporal gradient of derived reinforcement. American Journal of Psychology, 1950, 63, 237-243.

Krane, R. V., \& WAGNER, A. R. Taste aversion learning with a delayed shock US: Implications for the "generality of the laws of learning." Journal of Comparative and Physiological Psy. chology, 1975, 88, 882-889.

LEtT, B. T. Long delay learning in the T-maze. Learning and Motivation, 1975, 6, 80-90.

Mitchell, D., Scott, D. W., \& Mitchell, L. K. Attenuated and enhanced neophobia in the taste-aversion "delay of reinforcement" effect. Animal Learning \& Behavior, 1977, 5, 99-102.

PINe L, J. P. J. A short gradient of ECS-produced amnesia in a one-trial appetitive learning situation. Journal of Comparative and Physiological Psychology, 1969, 68, 650-655.

Tenen, S. S. Retrograde amnesia from electroconvulsive shock in a one-trial appetitive learning task. Science, 1965, 148, 12481250.

Testa, T. J., \& Ternes, J. W. Specificity of conditioning mechanisms in the modification of food preferences. In L. M. Barker, M. R. Best, \& M. Domjan (Eds.), Learning mechanisms in food selection. Waco, Tex: Baylor University Press, 1977.

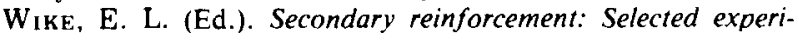
ments. New York: Harper \& Row, 1966.

(Received for publication January 31, 1980; revision accepted March 28,1980 .) 